\title{
Safety and Efficacy of Maxitrol in Pediatric Age Group Below Two Years With Adenoid Hypertrophy: A Retrospective Cohort Study
}

Mohammed Halawani ${ }^{1}$, Abdullah Alkhaldi ${ }^{2}$, Abdullah Almajed ${ }^{1}$, Ahmed Almutairi ${ }^{2}$, Maali Alrashed ${ }^{1}$, Nouf Albakeet ${ }^{1}$, Wala Alshiha ${ }^{1}$, Omar Aldibasi ${ }^{3}$, Jaber Alshammari ${ }^{1}$

1. Otolaryngology Head \& Neck Surgery, King Abdullah Specialized Children Hospital, King Abdulaziz Medical City, National Guard Health Affairs, Riyadh, SAU 2. Medicine, King Saud Bin Abdulaziz University for Health Sciences, Riyadh, SAU 3. Biostatistics and Bioinformatics, King Abdullah International Medical Research Center (KAIMRC), Riyadh, SAU

Corresponding author: Abdullah Alkhaldi, aabdulochik@gmail.com

\section{Abstract}

\section{Introduction}

Adenoid hypertrophy, a common condition in children, represents one of the common indications for surgery in pediatrics. Medical treatment alone is not effective, and most of the time patients are managed by surgical removal of the adenoid. The aim of this study is to assess the safety and efficacy of intranasal Maxitrol ${ }^{\circledR}$ drops (Novartis Pharmaceuticals, Basel, Switzerland) in pediatric patients with adenoid hypertrophy aged less than two years and to document any side effects during its use.

\section{Methods}

This retrospective cohort study was conducted at King Abdullah Specialist Children's Hospital (KASCH). We reviewed the charts of 86 pediatric patients aged less than two years who were diagnosed with adenoid hypertrophy between 2015 and 2018. Patients were grouped according to the type of intervention (use of Maxitrol ${ }^{\circledR}$, and no use). The follow-up time was up to one year.

\section{Results}

Out of 86 patients, 55 (63.9\%) patients had adenoid hypertrophy alone and 31 (36.1\%) had adenoid hypertrophy plus another disease. Patients with obstructive sleep apnea symptoms $(\mathrm{p}=0.026)$ and grade of adenoid ( $\mathrm{p}=0.040$ ) showed a significant relationship with surgery booking after one year. The probability of booking for surgery for those who used Maxitrol ${ }^{\circledR}$ was 1.394 times higher than for those who were not using it (odds ratio $[\mathrm{OR}]=1.394 ; 95 \%$ confidence interval $[\mathrm{CI}]=0.549-3.537$ ). Suppression of growth and eye complications were not reported in any of our patients.

Review began 02/08/2021 Review ended 04/23/2021 Published 04/28/2021

\section{○ Copyright 2021}

Halawani et al. This is an open access article distributed under the terms of the Creative Commons Attribution License CC-BY 4.0., which permits unrestricted use, distribution, and reproduction in any medium, provided the original author and source are credited.

\section{Conclusion}

In this small sample, the use of Maxitrol ${ }^{\circledR}$ in the pediatric age group below two years with adenoid hypertrophy was safe and effective in relieving nasal symptoms; however, eventually, surgery was needed in most of our patients. Suppression of growth and eye complications were not reported in any of our patients during the follow-up time.

Categories: Otolaryngology, Pediatrics

Keywords: adenoid hypertrophy, intranasal corticosteroids, maxitrol, intranasal steroids safety

\section{Introduction}

Adenoids are pyramid-shaped lymphoid tissue located in the nasopharynx [1]. Adenoid hypertrophy is a common disease in pediatrics. It usually presents with symptoms of airway obstruction such as mouth breathing and snoring [2]. Adenoid hypertrophy treatment in pediatrics is determined by the degree of airway obstruction and related comorbidities. Most of the time, it is treated by adenoidectomy. However, medical therapy is crucial and must be tried before surgical intervention. Various studies have been published about the use of intranasal corticosteroids in children, and they have shown promising results [38].

Intranasal corticosteroids have been used in pediatric patients aged less than two years at King Abdullah Specialist Children's Hospital to decrease nasal obstruction symptoms secondary to rhinitis and adenoid hypertrophy. They were the first line of therapy in patients with allergic rhinitis in the past few decades. However, they are not recommended for use in pediatric patients younger than two years due to a lack of evidence on their safety in this age group. 
To our knowledge, the use of intranasal Maxitrol ${ }^{\circledR}$ in pediatric patients below two years with adenoidal hypertrophy has not been investigated in the literature. Our study aims to assess intranasal Maxitrol's safety and efficacy in pediatric patients with adenoid hypertrophy aged less than two years and document any side effects during its use, such as eye complications and suppression of growth.

\section{Materials And Methods}

This retrospective cohort study was conducted at King Abdullah Specialist Children's Hospital, Riyadh, Saudi Arabia. We reviewed the charts and clinical information of pediatric patients aged less than two years who were diagnosed with adenoid hypertrophy between 2015 and 2018. The inclusion criteria were patients aged less than two years with adenoid hypertrophy as the primary disease and complete follow-up. We excluded patients who were using steroids (systemic/nebulizer) and patients with missing data. We reviewed 123 pediatric patients' files from our electronic healthcare system (BESTcare); however, only 86 patients met our inclusion criteria. Out of 86 patients, 47 used Maxitrol ${ }^{\circledR}$, while 39 did not take Maxitrol (control group). In our study, Maxitrol ${ }^{\circledR}$ (a sterile drop containing the active ingredients neomycin, polymyxin b, and dexamethasone) was used as two drops in each nostril per day for two to six weeks depending on symptoms improvement. The follow-up time was up to one year. The institutional review board approved this study at King Abdullah International Medical Research Center (RC20/016/R).

Statistical analyses were performed using SAS 9.4 (SAS Institute Inc., Cary, NC, USA), and the level of significance was declared at $\alpha=.05$. Categorical variables were presented as percentages, and frequencies continuous variables were reported in terms of means and standard deviations. Patient-specific characteristics included age, gender, height and weight, and the use of Maxitrol ${ }^{\circledR}$. Patients were grouped according to the type of intervention (use of Maxitrol ${ }^{\circledR}$, and no use) and compared across other variables using univariate analysis, including $\chi 2$ tests and Student $t$-test. Outcomes obtained included the date of surgery, local eye symptoms, effect on growth parameters, systemic symptoms, delay of surgery, and mortality.

Using booking for surgery within one year as an outcome variable, we compared the group who were booked for surgery within one year to the group who were not booked across other variables using univariate analysis, including $\chi 2$ tests and Student $t$-test. Further, a logistic regression model was applied to model the probability of booking surgery within one year.

\section{Results}

We analyzed 89 patients to examine the efficacy and safety of Maxitrol ${ }^{\circledR}$ in children below two years old with adenoid hypertrophy. As seen in Table 1, males were dominant (87.2\%), with nearly two-thirds (63.9\%) diagnosed with adenoid hypertrophy alone. Furthermore, $19.8 \%$ were presented without obstructive sleep apnea symptoms. The proportions of patients who reported snoring, sleep disturbance, and apnea were $15.1 \%, 43 \%$, and $66.7 \%$, respectively. The most commonly diagnosed grade of tonsil was grade 1 (45.3\%), followed by grade 2 (40.7\%). Likewise, 10.5\% presented with asthma and 3.5\% with Down syndrome. Furthermore, none of the patients presented with any eye complications. The mean height $(\mathrm{cm})$, weight $(\mathrm{kg})$, and BMI $(\mathrm{kg} / \mathrm{m} 2)$ of the patients were $77.7,9.89$, and 16.5 , respectively. Comparing the baseline characteristics of the patients in relation to the use of Maxitrol ${ }^{\circledR}$ revealed that male gender $(p<0.001)$, adenoid hypertrophy plus other diseases $(\mathrm{p}=0.007)$, and those without syndrome $(\mathrm{p}=0.028)$ were significantly more associated with the use of Maxitrol ${ }^{\circledR}$. 


\section{Cureus}

\begin{tabular}{|c|c|c|c|c|c|}
\hline Variables & Levels & Used Maxitrol@ (n=47) N(\%) & No Maxitrol $\odot(n=39)$ N(\%) & total & P-value \\
\hline Height at the first visit & & $77.74+8.9$ & $77.71+7.39$ & $77.72+8.2$ & 0.9870 \\
\hline Weight at the first visit & & $9.99+2.36$ & $9.77+1.68$ & $9.89+2.07$ & 0.6307 \\
\hline BMI at first visit & & $16.51+2.57$ & $16.49+2.11$ & $16.5+2.36$ & 0.9666 \\
\hline \multirow[t]{2}{*}{ Gender } & Male & 47 (62.67) & $28(37.33)$ & $75(87.20)$ & $<.0001>$ \\
\hline & Female & $0(0.00)$ & $11(100.00)$ & $11(12.79)$ & \\
\hline \multirow[t]{2}{*}{ Diagnosis } & Adenoid hypertrophy & $24(43.64)$ & $31(56.36)$ & $55(63.95)$ & 0.0073 \\
\hline & Adenoid hypertrophy+ other disease & $23(74.19)$ & $8(25.81)$ & $31(36.05)$ & \\
\hline \multirow[t]{4}{*}{ OSA symptoms } & No OSA symptoms & $5(29.41)$ & 12 (70.59) & $17(19.77)$ & 0.1265 \\
\hline & Snoring & $8(61.54)$ & $5(38.46)$ & $13(15.12)$ & \\
\hline & Sleep disturbance/mouth breathing & $21(56.76)$ & $16(43.24)$ & $37(43.02)$ & \\
\hline & Apnea/Cyanosis & $12(66.67)$ & $6(33.33)$ & $18(20.93)$ & \\
\hline \multirow[t]{4}{*}{ Grade of tonsil } & Grade 1 tonsil & $17(43.59)$ & $22(56.41)$ & $39(45.35)$ & 0.1992 \\
\hline & Grade 2 tonsil & $22(62.86)$ & 13 (37.14) & $35(40.7)$ & \\
\hline & Grade 3 tonsil & $6(60.00)$ & $4(40.00)$ & $10(11.63)$ & \\
\hline & Grade 4 tonsil & $2(100.00)$ & $0(0.00)$ & $2(2.33)$ & \\
\hline \multirow[t]{3}{*}{ Grade of adenoid } & Grade 1 adenoid & $7(50.00)$ & $7(50.00)$ & $14(16.28)$ & 0.4304 \\
\hline & Grade 2 adenoid & $13(46.43)$ & $15(53.57)$ & 28 (32.56) & \\
\hline & Grade 3 adenoid & $27(61.36)$ & $17(38.64)$ & $44(51.16)$ & \\
\hline \multirow[t]{2}{*}{ Asthma } & No asthma & $42(54.55)$ & $35(45.45)$ & $77(89.53)$ & 1.0000 \\
\hline & Asthma & $5(55.56)$ & $4(44.44)$ & $9(10.47)$ & \\
\hline \multirow[t]{3}{*}{ Syndromes } & No syndrome & $45(60.00)$ & $30(40.00)$ & 75 (87.21) & 0.0280 \\
\hline & Down syndrome & $1(33.33)$ & $2(66.67)$ & $3(3.49)$ & \\
\hline & Other syndromes & $1(12.50)$ & $2(66.67)$ & $8(9.3)$ & \\
\hline Eye complicatıons & No eye complications & $47(54.65)$ & $39(45.35)$ & $86(100)$ & \\
\hline
\end{tabular}

TABLE 1: Demographics and baseline clinical characteristics of all patients in relation to the use of Maxitrol ${ }^{\circ}$

BMI: body mass index; OSA: obstructive sleep apnea

Table 2 shows the relationship between the baseline characteristics and surgery booking after one year. The results reveal that obstructive sleep apnea (OSA) symptoms $(\mathrm{p}=0.026)$ and adenoid grade $(\mathrm{p}=0.040)$ show a significant relationship with surgery booking after one year. Other baseline characteristics, including height, weight, BMI, gender, diagnosis, tonsil grade, asthma, syndrome, and eye complications, did not show a significant relationship compared to surgery booking after one year (all p>0.05).

\begin{tabular}{|c|c|c|c|c|c|}
\hline Variables & Levels & $\begin{array}{l}\text { No surgery within } 1 \text { year }(n=45) \\
N(\%)\end{array}$ & $\begin{array}{l}\text { Booked for surgery }(n=41) \\
N(\%)\end{array}$ & Total & $\begin{array}{l}\text { P- } \\
\text { value }\end{array}$ \\
\hline $\begin{array}{l}\text { Height at the first } \\
\text { visit }\end{array}$ & & $76.84+8.49$ & $78.72+7.84$ & $\begin{array}{l}77.72 \\
+8.2\end{array}$ & 0.2921 \\
\hline $\begin{array}{l}\text { Weight at the first } \\
\text { visit }\end{array}$ & & $9.78+2.15$ & $10.02+2.01$ & $\begin{array}{l}9.89 \\
+2.07\end{array}$ & 0.5843 \\
\hline
\end{tabular}




\section{Cureus}

\begin{tabular}{|c|c|c|c|c|c|}
\hline BMI at first visit & & $16.83+2.54$ & $16.13+2.12$ & $\begin{array}{l}16.5 \\
+2.36\end{array}$ & 0.1751 \\
\hline \multirow[t]{2}{*}{ Gender } & Male & $38(50.67)$ & $37(49.33)$ & $75(87.20)$ & 0.5259 \\
\hline & Female & $7(63.64)$ & $4(36.36)$ & $\begin{array}{l}11 \\
(12.79)\end{array}$ & \\
\hline \multirow[t]{2}{*}{ Diagnosis } & Adenoid hypertrophy & $30(54.55)$ & 25 (45.45) & $\begin{array}{l}55 \\
(63.95)\end{array}$ & 0.6557 \\
\hline & $\begin{array}{l}\text { Adenoid hypertrophy+ other } \\
\text { disease }\end{array}$ & 15 (48.39) & $16(51.61)$ & $\begin{array}{l}31 \\
(36.05)\end{array}$ & \\
\hline \multirow[t]{4}{*}{ OSA symptoms } & No OSA symptoms & 12 (70.59) & $5(29.41)$ & $\begin{array}{l}17 \\
(19.77)\end{array}$ & 0.0258 \\
\hline & Snoring & $8(61.54)$ & $5(38.46)$ & $\begin{array}{l}13 \\
(15.12)\end{array}$ & \\
\hline & $\begin{array}{l}\text { Sleep disturbance/mouth } \\
\text { breathing }\end{array}$ & $20(54.05)$ & $17(45.95)$ & $\begin{array}{l}37 \\
(43.02)\end{array}$ & \\
\hline & Apnea/Cyanosis & $4(22.22)$ & 14 (77.78) & $\begin{array}{l}18 \\
(20.93)\end{array}$ & \\
\hline \multirow[t]{4}{*}{ Grade of tonsil } & Grade 1 tonsil & 19 (48.72) & $20(51.28)$ & $\begin{array}{l}39 \\
(45.35)\end{array}$ & 0.3978 \\
\hline & Grade 2 tonsil & $20(57.14)$ & $15(42.86)$ & $35(40.7)$ & \\
\hline & Grade 3 tonsil & $6(60.00)$ & $4(40.00)$ & $\begin{array}{l}10 \\
(11.63)\end{array}$ & \\
\hline & Grade 4 tonsil & $0(0.00)$ & $2(100.00)$ & $2(2.33)$ & \\
\hline \multirow[t]{3}{*}{ Grade of adenoid } & Grade 1 adenoid & $11(78.57)$ & $3(21.43)$ & $\begin{array}{l}14 \\
(16.28)\end{array}$ & 0.0403 \\
\hline & Grade 2 adenoid & 16 (57.14) & $12(42.86)$ & $\begin{array}{l}28 \\
(32.56)\end{array}$ & \\
\hline & Grade 3 adenoid & $18(40.91)$ & $26(59.09)$ & $\begin{array}{l}44 \\
(51.16)\end{array}$ & \\
\hline \multirow[t]{2}{*}{ Asthma } & No asthma & $42(54.55)$ & 35 (45.45) & $\begin{array}{l}77 \\
(89.53)\end{array}$ & 0.2993 \\
\hline & Asthma & $3(33.33)$ & $6(66.67)$ & $9(10.47)$ & \\
\hline \multirow[t]{3}{*}{ Syndromes } & No syndrome & $38(50.67)$ & 37 (49.33) & $\begin{array}{l}75 \\
(87.21)\end{array}$ & 0.7182 \\
\hline & Down syndrome & $2(66.67)$ & 1 (33.33) & $3(3.49)$ & \\
\hline & Other syndromes & $5(62.50)$ & $3(37.50)$ & $8(9.3)$ & \\
\hline Eye complications & No eye complications & $45(52.33)$ & $41(47.67)$ & $86(100)$ & \\
\hline
\end{tabular}

TABLE 2: Demographics and baseline clinical characteristics of all patients in relation to surgery booking after one year

BMI: body mass index; OSA: obstructive sleep apnea

The relationship between the use of Maxitrol ${ }^{\circledR}$ and booking for surgery was not statistically significant $(\mathrm{p}=0.26)$ as Table 3 shows. There was no significant difference in terms of surgery booking with Maxitrol ${ }^{\circledR}$ use. Patients without OSA symptoms were less likely to book a surgery than were those with apnea/cyanosis (odds ratio $[\mathrm{OR}]=0.133 ; 95 \%$ confidence interval $[\mathrm{CI}]=0.025-0.630$ ). Patients with sleep disturbance/mouth breathing are less likely to book surgery than are those with apnea/cyanosis $(\mathrm{OR}=0.249 ; 95 \% \mathrm{CI}=0.069$ - 
dry nose, bleeding, crusting, and candidiasis [17]. They are less likely to cause systemic effects on bone metabolism, effects on growth, and the adrenocortical axis [18]. Skoner et al. demonstrated the negative effect of intranasal beclomethasone dipropionate on growth after one year in pediatric patients (aged six to nine years) as it showed significant suppression of growth [19]. On the contrary, other studies have shown no suppression of bone growth in children after one year of treatment with a pediatric dose of mometasone furcate (MF) nasal spray (100 $\mu$ g daily) or with budesonide (BUD) $(200 \mu$ twice daily) [20,21]. Similarly, the use of Maxitrol ${ }^{\circledR}$ in our study had no effect on growth parameters in our patients when they were seen at their follow-up time after one year.

The age restriction for the use of intranasal corticosteroids is variable; for fluticasone furoate and mometasone, it is two years and older [22]. Mometasone furoate was found to be the most reliable drug in children older than two years [23,24]. None of the other studies have investigated, as we did, the use of intranasal corticosteroids in children younger than two years. Alhussien et al. suggested that intranasal use of fluticasone furoate, mometasone, and budesonide is safe if they are used at the recommended therapeutic dose after a proper medical evaluation during pregnancy [25]. Such a study can raise the question of whether intranasal steroids are safe during fetal periods and why they might be contraindicated during the first two years of life.

\section{Conclusions}

In this small sample, the use of Maxitrol ${ }^{\circledR}$ in the pediatric age group below two years with adenoid hypertrophy was safe and effective in relieving nasal symptoms; however, surgery was needed in most of our patients. Eye complications and suppression of growth were not reported in any of our patients during the follow-up time after one year. Further long-term large randomized clinical trials are needed to evaluate the safety and efficacy of Maxitrol ${ }^{\circledR}$.

\section{Additional Information \\ Disclosures}

Human subjects: Consent was obtained or waived by all participants in this study. King Abdullah International Medical Research Center (KAIMRC) issued approval RC20/016/R. The institutional review board approved this study at King Abdullah International Medical Research Center (RC20/016/R). Animal subjects: All authors have confirmed that this study did not involve animal subjects or tissue. Conflicts of interest: In compliance with the ICMJE uniform disclosure form, all authors declare the following: Payment/services info: All authors have declared that no financial support was received from any organization for the submitted work. Financial relationships: All authors have declared that they have no financial relationships at present or within the previous three years with any organizations that might have an interest in the submitted work. Other relationships: All authors have declared that there are no other relationships or activities that could appear to have influenced the submitted work.

\section{Acknowledgements}

The authors would like to thank Dr. Mohammed Alharbi and Dr. Ahmed Aldakil for their contributions in this study.

\section{References}

1. Bhargava R, Chakravarti A: A double-blind randomized placebo-controlled trial of topical intranasal mometasone furoate nasal spray in children of adenoidal hypertrophy with otitis media with effusion. Am J Otolaryngol. 2014, 35:766-70. 10.1016/j.amjoto.2014.06.006

2. Tankel JW, Cheesman AD: Symptom relief by adenoidectomy and relationship to adenoid and post-nasal airway size. J Laryngol Otol. 1986, 100:637-40. 10.1017/s0022215100099825

3. Demain JG, Goetz DW: Pediatric adenoidal hypertrophy and nasal airway obstruction: reduction with aqueous nasal beclomethasone. Pediatrics. 1995, 95:355-64.

4. Criscuoli G, D'Amora S, Ripa G, Cinquegrana G, Mansi N, Impagliazzo N, Pisacane A: Frequency of surgery among children who have adenotonsillar hypertrophy and improve after treatment with nasal beclomethasone. Pediatrics. 2003, 111:e236-8. 10.1542/peds.111.3.e236

5. Berlucchi M, Valetti L, Parrinello G, Nicolai P: Long-term follow-up of children undergoing topical intranasal steroid therapy for adenoidal hypertrophy. Int J Pediatr Otorhinolaryngol. 2008, 72:1171-5. 10.1016/j.ijporl.2008.04.001

6. Brouillette RT, Manoukian JJ, Ducharme FM, Oudjhane K, Earle LG, Ladan S, Morielli A: Efficacy of fluticasone nasal spray for pediatric obstructive sleep apnea. J Pediatr. 2001, 138:838-44. 10.1067/mpd.2001.114474

7. Cengel S, Akyol MU: The role of topical nasal steroids in the treatment of children with otitis media with effusion and/or adenoid hypertrophy. Int J Pediatr Otorhinolaryngol. 2006, 70:639-45. 10.1016/j.ijporl.2005.08.013

8. Ciprandi G, Varricchio A, Capasso M, et al.: Intranasal flunisolide treatment in children with adenoidal hypertrophy. Int J Immunopathol Pharmacol. 2007, 20:833-6. 10.1177/039463200702000420

9. Tadros M: Anatomical distribution of nasal steroid spray versus nebulized nasal steroid . Otolaryngol Head Neck Surg. 2003, 129:247.

10. Weber R, Keerl R, Radziwill R, et al.: Videoendoscopic analysis of nasal steroid distribution. Rhinology. 
1999, 37:69-73

11. Demirhan H, Aksoy F, Ozturan O, Yildirim YS, Veyseller B: Medical treatment of adenoid hypertrophy with "fluticasone propionate nasal drops". Int J Pediatr Otorhinolaryngol. 2010, 74:773-6.

10.1016/j.ijporl.2010.03.051

12. Berlucchi M, Salsi D, Valetti L, Parrinello G, Nicolai P: The role of mometasone furoate aqueous nasal spray in the treatment of adenoidal hypertrophy in the pediatric age group: preliminary results of a prospective, randomized study. Pediatrics. 2007, 119:e1392-7. 10.1542/peds.2006-1769

13. Zhang L, Mendoza-Sassi RA, César JA, Chadha NK: Intranasal corticosteroids for nasal airway obstruction in children with moderate to severe adenoidal hypertrophy. Cochrane Database Syst Rev. 2008, CD006286. 10.1002/14651858.CD006286.pub2

14. Chohan A, Lal A, Chohan K, Chakravarti A, Gomber S: Systematic review and meta-analysis of randomized controlled trials on the role of mometasone in adenoid hypertrophy in children. Int J Pediatr Otorhinolaryngol. 2015, 79:1599-608. 10.1016/j.ijporl.2015.07.009

15. Modrzyński M, Zawisza E, Mazurek H: [The influence of medical treatment of the perennial allergic rhinitis on the adenoid size in children]. Otolaryngol Pol. 2006, 60:543-50.

16. Varricchio A, Tortoriello G, Capasso M, et al.: Prevention of surgery in children with adenoidal hypertrophy treated with intranasal flunisolide: a 12-month follow-up. J Biol Regul Homeost Agents. 2009, 23:95-101.

17. Mabry RL: Corticosteroids in the management of upper respiratory allergy: the emerging role of steroid nasal sprays. Otolaryngol Head Neck Surg. 1992, 107:855-9; discussion 859-60. 10.1177/019459989210700608.2

18. Ferguson AC, Spier S, Manjra A, Versteegh FG, Mark S, Zhang P: Efficacy and safety of high-dose inhaled steroids in children with asthma: a comparison of fluticasone propionate with budesonide. J Pediatr. 1999, 134:422-7. 10.1016/s0022-3476(99)70198-8

19. Skoner DP, Rachelefsky GS, Meltzer EO, et al.: Detection of growth suppression in children during treatment with intranasal beclomethasone dipropionate. Pediatrics. 2000, 105:E23. 10.1542/peds.105.2.e23

20. Schenkel EJ, Skoner DP, Bronsky EA, et al.: Absence of growth retardation in children with perennial allergic rhinitis after one year of treatment with mometasone furoate aqueous nasal spray. Pediatrics. 2000, 105:E22. 10.1542/peds.105.2.e22

21. Möller C, Ahlström H, Henricson KA, Malmqvist LA, Akerlund A, Hildebrand H: Safety of nasal budesonide in the long-term treatment of children with perennial rhinitis. Clin Exp Allergy. 2003, 33:816-22. 10.1046/j.1365-2222.2003.01689.x

22. Wallace DV, Dykewicz MS, Bernstein DI, et al.: The diagnosis and management of rhinitis: an updated practice parameter. J Allergy Clin Immunol. 2008, 122:S1-84. 10.1016/j.jaci.2008.06.003

23. Derendorf H, Meltzer EO: Molecular and clinical pharmacology of intranasal corticosteroids: clinical and therapeutic implications. Allergy. 2008, 63:1292-300. 10.1111/j.1398-9995.2008.01750.x

24. Minshall E, Ghaffar O, Cameron L, et al.: Assessment by nasal biopsy of long-term use of mometasone furoate aqueous nasal spray (Nasonex) in the treatment of perennial rhinitis. Otolaryngol Head Neck Surg. 1998, 118:648-54. 10.1177/019459989811800514

25. Alhussien AH, Alhedaithy RA, Alsaleh SA: Safety of intranasal corticosteroid sprays during pregnancy: an updated review. Eur Arch Otorhinolaryngol. 2018, 275:325-33. 10.1007/s00405-017-4785-3 